Research Paper

\title{
Serum Unsaturated Free Fatty Acids: A Potential Biomarker Panel for Differentiating Benign Thyroid Diseases from Thyroid Cancer
}

\author{
Yaping Zhang1, Ling Qiu², Chengyan $\mathrm{He}^{3}$, Yanmin Wang4, Yujie liu¹, Dan Zhang1, Zhili Li1, ${ }^{1}$ \\ 1. Department of Biophysics and Structural Biology, Institute of Basic Medical Sciences, Chinese Academy of Medical Sciences \& School of Basic \\ Medicine, Peking Union Medical College, Beijing 100005, PR China \\ 2. Department of Clinical Laboratory, Peking Union Medical College Hospital, Chinese Academy of Medical Sciences \& Peking Union Medical \\ College, Beijing 100730, PR China \\ 3. Clinical Lab Diagnosis, China-Japan Union Hospital, Jilin University, Changchun 130041, PR China \\ 4. Department of Clinical Laboratory, Heze Municipal Hospital, Shandong 1740031, PR China
}

$\triangle$ Corresponding author: Zhili Li, Department of Biophysics and Structural Biology, Institute of Basic Medical Sciences, Chinese Academy of Medical Sciences \& School of Basic Medicine, Peking Union Medical College, 5 Dongdan San Tiao, Beijing 100005, China. E-mail: lizhili@ibms.pumc.edu.cn. Tel/Fax: +86-10-69156479

() 2015 Ivyspring International Publisher. Reproduction is permitted for personal, noncommercial use, provided that the article is in whole, unmodified, and properly cited. See http://ivyspring.com/terms for terms and conditions.

Received: 2015.04.17; Accepted: 2015.08.31; Published: 2015.10.20

\begin{abstract}
Background: Serum free fatty acids (FFAs) are correlated with pathological status, and change in serum FFA levels may be associated with thyroid diseases.

Materials and Methods: In this study, 664 serum samples from 322 healthy controls, 129 patients with benign thyroid disease (BTD), and 213 patients with thyroid cancer (TC) were collected. Chip-based direct-infusion nanoelectrospray-mass spectrometry was performed to simultaneously quantify six serum FFAs (i.e., $\mathrm{C}_{16: 1}, \mathrm{C}_{18: 1}, \mathrm{C}_{18: 2}, \mathrm{C}_{18: 3}, \mathrm{C}_{20: 4}$, and $\mathrm{C}_{22: 6}$ ), with the excellent correlation coefficients of $>0.99$ and relative standard deviation of $<18 \%$ for all analysts. The Mann-Whitney $U$ test was used to compare the differences in serum FFA levels between three above-mentioned groups.

Results: Significant increase in the levels of $C_{16: 1}, C_{18: 1}, C_{18: 2}, C_{18: 3}, C_{20: 4}$, and $C_{22: 6}$ in healthy controls relative to TC patients and BTD patients was observed, and the levels of $C_{16: 1}, C_{18: 2}, C_{20: 4}$, and $C_{22: 6}$ in BTD patients were significantly decreased relative to TC patients. Receiver operating characteristic (ROC) analysis indicated that a combination of $\mathrm{C}_{16: 1}, \mathrm{C}_{18: 2}, \mathrm{C}_{20: 4}$, and $\mathrm{C}_{22: 6}$ has excellent diagnostic performance to differentiate BTD patients from TC patients, with an area under the ROC curve of 0.857 , a sensitivity of $76.8 \%$, and a specificity of $83.7 \%$.

Conclusions: Change in serum levels of FFAs is closely correlated with thyroid diseases, and a biomarker panel $\left(\mathrm{C}_{16: 1}, \mathrm{C}_{18: 2}, \mathrm{C}_{20: 4}\right.$, and $\left.\mathrm{C}_{22: 6}\right)$ should be of benefit to differentiate $\mathrm{BTD}$ patients from TC patients.
\end{abstract}

Key words: thyroid diseases; biomarker panel; unsaturated free fatty acids; serum.

\section{Introduction}

Thyroid cancer (TC) is the most common endocrine malignancy. Incidence of TC has been increasing in the last decade, with approximately three times higher in females than in males [1-3]. Routine inspection is difficult to differentiate benign tumor from malignant thyroid nodules. At present, ultrasonog- raphy-guided fine needle aspiration biopsy is the most commonly used diagnostic tool for diagnosing thyroid diseases, especially for small nodules (< $1.5 \mathrm{~cm}$ ) and nonpalpable thyroid nodules [4]. In addition, diffusion-weighted MR imaging is another vital diagnostic tool for evaluating in vivo tumor charac- 
terization and has the potential to differentiate benign from malignant nodules in the thyroid [5-7], but it lacks standard b-values. Hence, it is necessary to screen noninvasive, inexpensive, and sensitive serum biomarkers for differentiating benign thyroid nodules from malignant thyroid nodules.

Serum free fatty acids (FFAs) are important bioactive molecules and are involved in many important metabolic pathways. Emerging evidences have shown that essential fatty acids can modulate the interaction between hormones and their receptors, which can change the expression of receptors on the cells [8]. Our previous studies have suggested that significantly decreased unsaturated FFAs (i.e., $C_{16: 1}, C_{18: 1}, C_{18: 2}, C_{18: 3}$, $\mathrm{C}_{20: 4}$, and $\mathrm{C}_{22: 6)}$ are closely correlated with pancreatic cancer [9], lung cancer [10], and breast cancer [11].

In the present study, we have employed chip-based direct-infusion nanoelectrosprayFourier transform ion cyclotron resonance mass spectrometry (CBDInano ESI-FTICR MS) to simultaneously quantify six FFAs (i.e., $\mathrm{C}_{16: 1}, \mathrm{C}_{18: 3}, \mathrm{C}_{18: 2}, \mathrm{C}_{18: 1}, \mathrm{C}_{20: 4}$, and $\mathrm{C}_{22: 6)}$ in 664 serum samples from 322 healthy controls, 129 patients with benign thyroid diseases (BTD), and 213 TC patients. Mann-Whitney U test was used to compare differences in serum FFA levels between BTD patients, TC patients, and healthy controls. Our data indicate that a combination of $\mathrm{C}_{16: 1 \text {, }}$ $\mathrm{C}_{18: 2,} \mathrm{C}_{20: 4}$, and $\mathrm{C}_{22: 6}$ has excellent diagnostic accuracy to differentiate BTD patients from TC patients, with an area under the receiver operating characteristic (ROC) curve (AUC) of 0.857 , a sensitivity of $76.8 \%$, and a specificity of $83.7 \%$.

\section{Materials and Methods}

\section{Chemicals and Reagents}

Palmitic acid $\left(\mathrm{C}_{16: 0}\right.$, purity $\left.>99 \%\right)$ was from $\mathrm{J} \& \mathrm{~K}$ (J\&K Scientific Ltd, China). Other fatty acids such as palmitoleic acid $\left(\mathrm{C}_{16: 1}\right)$, heptadecenoic acid $\left(\mathrm{C}_{17: 1}\right)$, linolenic acid $\left(\mathrm{C}_{18: 3}\right)$, linoleic acid $\left(\mathrm{C}_{18: 2}\right)$, oleic acid $\left(\mathrm{C}_{18: 1}\right)$, arachidonic acid $\left(\mathrm{C}_{20: 4}\right)$, heneicosanoic acid $\left(\mathrm{C}_{21: 0}\right)$, docosahexaenoic acid $\left(\mathrm{C}_{22: 6}\right)$, and ammonium acetate (all purity $>99 \%$, except for $\mathrm{C}_{22: 6}$ with purity $>98 \%$ ) were from Sigma-Aldrich Chemicals. HPLC-grade methanol, ethanol, and acetonitrile were from Fisher Scientific (Pittsburg, PA, USA). The ultrapure water was purified using a Milli-Q system (Millipore, USA).

\section{Participants}

In this study, 664 participants were recruited, including 322 healthy controls, 129 BTD patients, and 213 TC patients. Healthy controls were from China-Japan Union Hospital ( $\mathrm{n}=150$, Changchun, China) and Heze Municipal Hospital ( $n=172$, Heze, China), respectively. TC patients were from China-Japan Union Hospital $(\mathrm{n}=88)$ and from Peking Union Medical
College Hospital ( $n=129$, Beijing, China), respectively. All 129 BTD patients were from Peking Union Medical College Hospital. All serum samples used in this study were the remaining sera after clinical laboratory examination, and collected in the morning after overnight fasting of approximately $12 \mathrm{~h}$. All experiments were performed in accordance with relevant guidelines and regulations. The participants gave informed consents, and the study was approved by the Ethics Review Board at the Institute of Basic Medical Sciences, Chinese Academy of Medical Sciences.

\section{Study design}

Characteristics of all participants are shown in Table 1. Serum samples from TC patients were classified into two sets: the training set $(n=88)$ and the validation set $(n=125)$. Healthy controls were age- and sex-matched to TC patients in the training set $(n=150)$ and the validation set $(n=172)$, respectively, and 129 age-and sex-matched BTD patients were put into the validation set to compare differences between healthy controls, TC patients, and BTD patients.

Table 1. Demographic and clinical characteristics of all participants in the training set and validation set

\begin{tabular}{llllll}
\hline & Training Set & \multicolumn{4}{c}{ Validation Set } \\
\cline { 2 - 6 } & $\begin{array}{l}\text { Controls } \\
(\mathbf{n = 1 5 0 )}\end{array}$ & $\begin{array}{l}\text { TC } \\
(\mathbf{n = 8 8})\end{array}$ & $\begin{array}{l}\text { Controls } \\
(\mathbf{n = 1 7 2})\end{array}$ & $\begin{array}{l}\text { BTD } \\
(\mathbf{n = 1 2 9})\end{array}$ & $\begin{array}{l}\text { TC } \\
(\mathbf{n}=\mathbf{1 2 5})\end{array}$ \\
\hline $\begin{array}{l}\text { Male/Female } \\
\text { Age(years) }\end{array}$ & $73 / 77$ & $26 / 62$ & $82 / 90$ & $49 / 80$ & $22 / 103$ \\
Mean \pm SD & $45.9 \pm 9.2$ & $45.6 \pm 10.2$ & $47.2 \pm 10.3$ & $47.5 \pm 13.0$ & $47.9 \pm 10.6$ \\
Range & $24-73$ & $26-75$ & $22-76$ & $21-75$ & $22-75$ \\
\hline
\end{tabular}

SD: standard deviation; TC: thyroid cancer; BTD: benign thyroid disease.

\section{Standard solutions and sample preparation}

The calibration standard solutions and serum samples were prepared as our own previous study [9]. Briefly, the final concentrations of $83.3 \mathrm{nM}$ heptadecenoic acid $\left(\mathrm{C}_{17: 1}\right)$ and $33.3 \mathrm{nM}$ heneicosanoic acid $\left(\mathrm{C}_{21: 0}\right)$ as a mixed internal standard (IS) were prepared in ethanol. For calibration standard solutions, a mixture of $\mathrm{C}_{16: 1}(342.0 \mu \mathrm{M}), \mathrm{C}_{18: 3}(81.7 \mu \mathrm{M}), \mathrm{C}_{18: 2}(569.0$ $\mu \mathrm{M}), \mathrm{C}_{18: 1}(836.0 \mu \mathrm{M}), \mathrm{C}_{20: 4}(183.0 \mu \mathrm{M})$, and $\mathrm{C}_{22: 6}(56.2$ $\mu \mathrm{M})$ was dissolved in ethanol, and the diluted 500 -fold solution by methanol/acetonitrile/5 mM ammonium acetate in water $(42 / 28 / 30, \mathrm{v} / \mathrm{v} / \mathrm{v})$ was termed as STD1(684.0 $\mathrm{nM} \mathrm{C}_{16: 1}, 163.5 \mathrm{nM} \mathrm{C} \mathrm{C}_{18: 3}, 1138.0$ $\mathrm{nM} \mathrm{C}_{18: 2,}, 1672.0 \mathrm{nM} \mathrm{C}_{18: 1}, 366.0 \mathrm{nM} \mathrm{C}_{20: 4}$, and $112.3 \mathrm{nM}$ $\mathrm{C}_{22: 6)}$. Then the STD1 was further diluted 2-, 10-, 20-, 50- and 80-fold, termed as STD2, STD3, STD4, STD5, and STD6, respectively. These standard solutions were further mixed with $1 \mu \mathrm{L}$ of the IS solution. The above-mentioned mixtures were employed to construct calibration equations for each of serum FFAs. 
The STD3 as a quality control sample was also utilized to estimate the experimental reproducibility, and It was analyzed once every 10 test samples during the entire experiment.

After thawing at $4{ }^{\circ} \mathrm{C}, 50 \mu \mathrm{L}$ aliquot of each serum sample was mixed with $950 \mu \mathrm{L}$ of methanol/acetonitrile $(3 / 2, \mathrm{v} / \mathrm{v})$ to precipitate serum proteins followed by vortex-mixing for $30 \mathrm{~s}$ and stored at $-20{ }^{\circ} \mathrm{C}$ overnight. The resulting mixture was centrifuged at $19000 \mathrm{~g}$ for $30 \mathrm{~min}$ to obtain supernatant, followed by mixing $20 \mu \mathrm{L}$ aliquot of the supernatant with $1 \mu \mathrm{L}$ of the IS solution, $500 \mu \mathrm{L}$ of hexane, and 500 $\mu \mathrm{L}$ of water, and then vortexed for $30 \mathrm{~s}$. After centrifugation at $1500 \mathrm{~g}$ for $10 \mathrm{~min}$, the upper hexane layer was transferred into a glass vial and air-dried. The dried sample was re-dissolved by $1 \mathrm{~mL}$ of methanol/acetonitrile/5 $\mathrm{mM}$ ammonium acetate $(42 / 28 / 30, v / v / v)$ in water for mass spectrometric analysis.

\section{Mass Spectrometry}

All experiments were performed by a $9.4 \mathrm{~T}$ Apex-ultra ${ }^{\mathrm{TM}}$ hybrid Qh-FTICR MS (Bruker Daltonics, Billerica, MA, USA) equipped with a NanoMate system (Advion BioSciences). The NanoMate system includes a cooling unit set at $4{ }^{\circ} \mathrm{C}$ to cool sample solutions and nanoelectrospray source, which includes a 96-well plate, conductive pipette tips, and nanoChip with a $20 \times 20$ array of nozzle. The sample volume of $0.1 \mu \mathrm{L}$ was directly infused using a low delivery gas pressure of $0.7 \mathrm{psi}$, and a voltage of $-1.8 \mathrm{kV}$ was applied to the nozzle to generate nanoelectrospray at a flow rate of approximately $100 \mathrm{~nL} / \mathrm{min}$.

A mass spectrum was accumulated by 10 full scans over the $m / z$ range of $150-400$ with the resolution of 200,000 at $\mathrm{m} / \mathrm{z} 400$. A mixture of $\mathrm{C}_{15: 0}$ (molecular weight, $242.22458 \mathrm{Da}), \mathrm{C}_{17: 0}(270.25588 \mathrm{Da})$, and $\mathrm{C}_{21: 0}$ (326.31848 Da) was used to calibrate the instrument. All mass spectra were processed using DataAnalysis 4.0 (Bruker Daltonics). The FFAs were identified based on their observed accurate molecular masses relative to theoretical values with the mass error of $\leq$ $0.00029 \mathrm{Da}$ and reliable isotope distribution relative to theoretical distribution with relative standard deviation (RSD) of $<2 \%$. The baseline intensity in each spectrum was adopted as their intensities of missing FFAs.

\section{Statistical analysis}

The Mann-Whitney U test was used to compare differences in serum FFA levels between healthy controls, BTD patients, and TC patients. Significantly changed FFAs $(p<0.05)$ were submitted to ROC curve analysis to assess their diagnostic accuracy. For the training study, the AUC value, sensitivity, and speci- ficity were obtained based on an optimal cut-off value. For the validation study, the diagnostic models were re-evaluated in term of the cut-off values from the training study. A $p$ value of $<0.05$ was considered to be statistically significant. All statistical analyses were performed by the SPSS software (version 16.0, Chicago, IL, USA).

\section{Results and Discussion}

\section{Quantitative and qualitative analysis of serum FFAs}

The CBDInanoESI-FTICR MS platform was employed to simultaneously quantify the levels of serum FFAs in 664 participant sera. Calibration equations between the concentration ratios of each fatty acid to IS ( $C_{17: 1}$ as IS of $C_{16: 1}, C_{18: 3}, C_{18: 2}$, and $C_{18: 1}$ and $C_{21: 0}$ as IS of $\mathrm{C}_{20: 4}$ and $\mathrm{C}_{22: 6}$ ) and their corresponding intensity ratios were established, with the correlation coefficients of $>0.993$ (Table 2). 68 mass spectra of the quality control sample showed that the RSDs for all analytes were less than $<18 \%$ during the entire experiment, indicating that the experimental stability is acceptable for complex biological samples (Table 2), and that high-throughput CBDInanoESI-mass spectrometry is a promising platform for rapid quantification of serum FFAs. Representative mass spectra of serum FFAs from one healthy control, one BTD patient, and one TC patient are shown in Fig. 1. Six FFA levels were computed on the basis of their respective calibration equations.

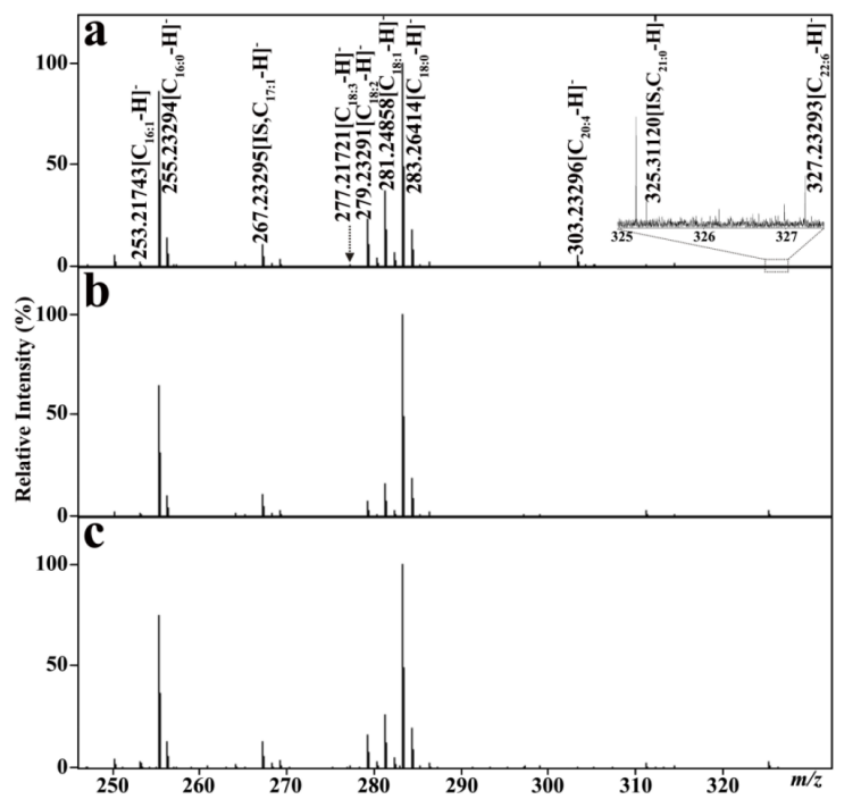

Figure 1. Representative negative ion mass spectra of serum FFAs. (a) one healthy control. (b) one patient with benign thyroid diseases, and (c) one patient with thyroid cancer. 
Table 2. Calibration equations, correlation coefficient $\left(R^{2}\right)$, and experimental stability of FAs

\begin{tabular}{lllll}
\hline FAs & \multicolumn{2}{l}{ Linearity $(\mathrm{n}=3)$} & \multicolumn{2}{l}{$\begin{array}{l}\text { RSD } \\
(\%)\end{array}$} \\
\cline { 2 - 4 } & $\mathrm{FA}(\mathrm{nM})$ & Equation & $\mathrm{R}^{2}$ & $<15$ \\
\hline $\mathrm{C}_{16: 1}$ & $8.5-684.0$ & $\mathrm{Y}=0.473( \pm 0.018) \mathrm{X}+0.039( \pm 0.011)$ & 0.998 & $<15$ \\
$\mathrm{C}_{18: 3}$ & $2.0-163.5$ & $\mathrm{Y}=1.301( \pm 0.052) \mathrm{X}-0.030( \pm 0.010)$ & 0.999 & $<18$ \\
$\mathrm{C}_{18: 2}$ & $14.2-1138.0$ & $\mathrm{Y}=1.614( \pm 0.066) \mathrm{X}-0.127( \pm 0.057)$ & 0.998 & $<17$ \\
$\mathrm{C}_{18: 1}$ & $20.9-1672.0$ & $\mathrm{Y}=1.640( \pm 0.029) \mathrm{X}+0.464( \pm 0.125)$ & 0.994 & $<17$ \\
$\mathrm{C}_{20: 4}$ & $4.6-366.0$ & $\mathrm{Y}=0.886( \pm 0.039) \mathrm{X}-0.063( \pm 0.044)$ & 0.995 & $<10$ \\
$\mathrm{C}_{22: 6}$ & $1.4-112.3$ & $\mathrm{Y}=0.714( \pm 0.035) \mathrm{X}-0.029( \pm 0.010)$ & 0.997 & $<13$
\end{tabular}

$\mathrm{X}$ : Concentration ratios of individual FAs to IS $\left(83.3 \mathrm{nM}\right.$ for $\mathrm{C}_{17: 1}$ and $33.3 \mathrm{nM}$ for $\mathrm{C}_{21: 0) \text {; }}$

Y: Corresponding intensity ratios of FAs to IS; RSD, relative standard deviation.

\section{Association of change in serum FFA levels with physiological status}

In the training set, comparison of healthy controls and TC patients was performed using Mann-Whitney $U$ test. It was found that significantly decreased FFAs $\left(\mathrm{C}_{16: 1}, \mathrm{C}_{18: 3}, \mathrm{C}_{18: 2}, \mathrm{C}_{18: 1}, \mathrm{C}_{20: 4}\right.$, and $\left.\mathrm{C}_{22: 6}\right)$ in TC patients were observed relative to healthy controls $(p<0.01$, Fig. 2). Change trends in the levels of polyunsaturated fatty acids (PUFAs) (i.e., $\mathrm{C}_{18: 2,} \mathrm{C}_{20: 4 \text {, }}$ and $\left.\mathrm{C}_{22: 6}\right)$ are in agreement with the previous data detected in the urine of thyroid cancer patients [12]. The ROC curve analysis was performed for each FFA and their combinations, and the results are listed in Table 3. As shown in Table 3, panel a (a combination of $\mathrm{C}_{16: 1}, \mathrm{C}_{18: 3}, \mathrm{C}_{18: 2}, \mathrm{C}_{18: 1}, \mathrm{C}_{20: 4}$, and $\mathrm{C}_{22: 6}$ ) has high diagnostic performance to differentiate TC patients from healthy controls, with an AUC value of 0.847 , a sensitivity of $73.9 \%$, and a specificity of $86.0 \%$ in the training study. The ROC curve for panel a is shown in Fig. 3a.

To confirm the association of serum FFA levels with TC, Mann-Whitney U test was further used to an independent validation study including 172 healthy controls, 129 BTD patients, and 125 TC patients, and the results are shown in Fig. 2. The ROC curve analysis results for each FFA and their combinations are listed in Table 3. In accordance with the training study, significant decreases in the levels of $\mathrm{C}_{16: 1}, \mathrm{C}_{18: 3}$, $\mathrm{C}_{18: 2}, \mathrm{C}_{18: 1}, \mathrm{C}_{20: 4}$, and $\mathrm{C}_{22: 6}$ in TC patients relative to healthy controls were observed, and high diagnostic ability of panel a to differentiate TC patients from healthy controls was observed, with an AUC value of 0.873 , a sensitivity of $81.6 \%$, and a specificity of $80.8 \%$. The ROC curve for panel a is shown in Fig. $\mathbf{3 b}$.
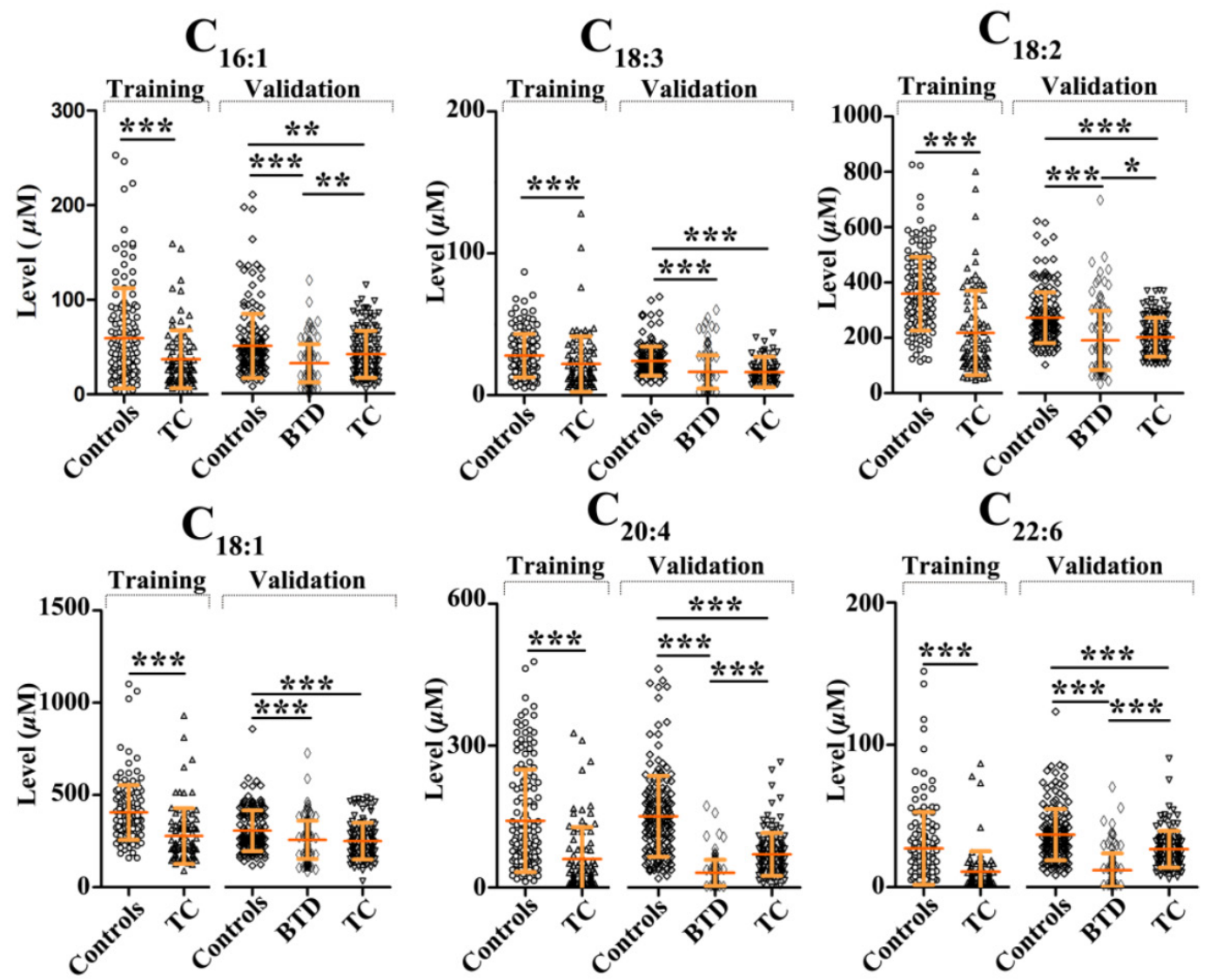

Figure 2. Scatter plots of serum levels of $C_{16: 1}, C_{18: 3}, C_{18: 2}, C_{18: 1}, C_{20: 4}$, and $C_{22: 6}$ in healthy controls, patients with benign thyroid disease, and patients with thyroid cancer in the training set and validation set. *, $p<0.05 ; * *, p<0.01 ; * * *, p<0.001$. 
Table 3. The AUC values, cut-off values, sensitivity, and specificity of significantly expressed FFAs between controls and patients

\begin{tabular}{|c|c|c|c|c|c|c|c|c|c|c|c|c|c|c|c|}
\hline \multirow[t]{3}{*}{ FFAs } & \multirow{2}{*}{\multicolumn{4}{|c|}{$\begin{array}{c}\text { Training set } \\
\text { Controls vs. TC }\end{array}$}} & \multicolumn{11}{|c|}{ Validation set } \\
\hline & & & & & \multicolumn{3}{|c|}{ Controls vs. TC } & \multicolumn{4}{|c|}{ Controls vs. BTD } & \multicolumn{4}{|c|}{ BTD vs. TC } \\
\hline & AUC (95\% CI) & $\begin{array}{l}\text { Sens } \\
(\%)\end{array}$ & $\begin{array}{l}\text { Spec } \\
(\%)\end{array}$ & $\begin{array}{l}\text { cut- } \\
\text { off }\end{array}$ & AUC (95\% CI) & $\begin{array}{l}\text { Sens } \\
(\%)\end{array}$ & $\begin{array}{l}\text { Spec } \\
(\%)\end{array}$ & AUC (95\% CI) & $\begin{array}{l}\text { Sens } \\
(\%)\end{array}$ & $\begin{array}{l}\text { Spec } \\
(\%)\end{array}$ & $\begin{array}{l}\text { cut- } \\
\text { off }\end{array}$ & AUC (95\% CI) & $\begin{array}{l}\text { Sens } \\
(\%)\end{array}$ & $\begin{array}{l}\text { Spec } \\
(\%)\end{array}$ & $\begin{array}{l}\text { cut- } \\
\text { off }\end{array}$ \\
\hline $\mathrm{C}_{16: 1}$ & $0.647(.576-.718)$ & 54.7 & 68.2 & 36.6 & $0.589(.521-.658)$ & 58.1 & 54.4 & $0.699(.638-.760)$ & 78.5 & 55.0 & 30.3 & $0.611(.543-.680)$ & 60.0 & 54.3 & 29.4 \\
\hline $\mathrm{C}_{18: 3}$ & $0.656(.582-.730)$ & 72.0 & 55.7 & 17.1 & $0.803(.750-.857)$ & 85.5 & 68.8 & $0.779(.720-.839)$ & 82.6 & 72.9 & 16.8 & & & & \\
\hline$C_{18: 2}$ & $0.789(.723-.854)$ & 88.0 & 63.6 & 220.8 & 0.732(.673-.792) & 73.3 & 64.8 & $0.769(.710-.828)$ & 89.0 & 61.2 & 185.7 & $0.586(.516-.657)$ & 56.0 & 62.8 & 189.1 \\
\hline$C_{18: 1}$ & $0.787(.722-.852)$ & 88.7 & 59.1 & 254.6 & 0.652(.588-.716) & 59.3 & 59.2 & $0.627(.562-.691)$ & 77.3 & 46.5 & 233.0 & & & & \\
\hline$C_{20: 4}$ & $0.781(.718-.844)$ & 78.7 & 67.0 & 53.1 & $0.818(770-.867)$ & 72.1 & 80.8 & $0.956(.935-.977)$ & 87.2 & 91.5 & 63.4 & $0.818(.765-.871)$ & 72.8 & 82.2 & 43.1 \\
\hline$C_{22: 6}$ & $0.816(.759-.874)$ & 82.0 & 67.0 & 9.1 & 0.692(.631-.752) & 80.2 & 45.6 & $0.912(.876-.947)$ & 83.7 & 86.8 & 21.9 & $0.851(.802-.900)$ & 84.0 & 77.5 & 15.8 \\
\hline PUFA & $0.845(.790-.900)$ & 68.2 & 90.0 & 0.5 & $0.870(.828-.912)$ & 76.0 & 84.3 & $0.960(.941-.979)$ & 83.7 & 95.3 & 0.7 & & & & \\
\hline Panel a & $0.847(.793-.901)$ & 73.9 & 86.0 & 0.5 & $0.873(.832-.915)$ & 81.6 & 80.8 & $0.968(.951-.985)$ & 87.6 & 95.3 & 0.7 & & & & \\
\hline Panel b & & & & & & & & & & & & $0.857(.810-.903)$ & 79.8 & 83.7 & 0.5 \\
\hline
\end{tabular}

TC: thyroid cancer; BTD: benign thyroid diseases; Sens: Sensitivity; Spec: Specificity; PUFA: polyunsaturated fatty acid; Panel a: $C_{16: 1}, C_{18: 3}, C_{18: 2}, C_{18: 1}, C_{20: 4}$ and $C_{22: 6}$ Panel b: $\mathrm{C}_{16: 1}, \mathrm{C}_{18: 2}, \mathrm{C}_{20: 4}$, and $\mathrm{C}_{22: 6}$, AUC: area under the receiver operating characteristic curve; $\mathrm{CI}$ : confidential interval.
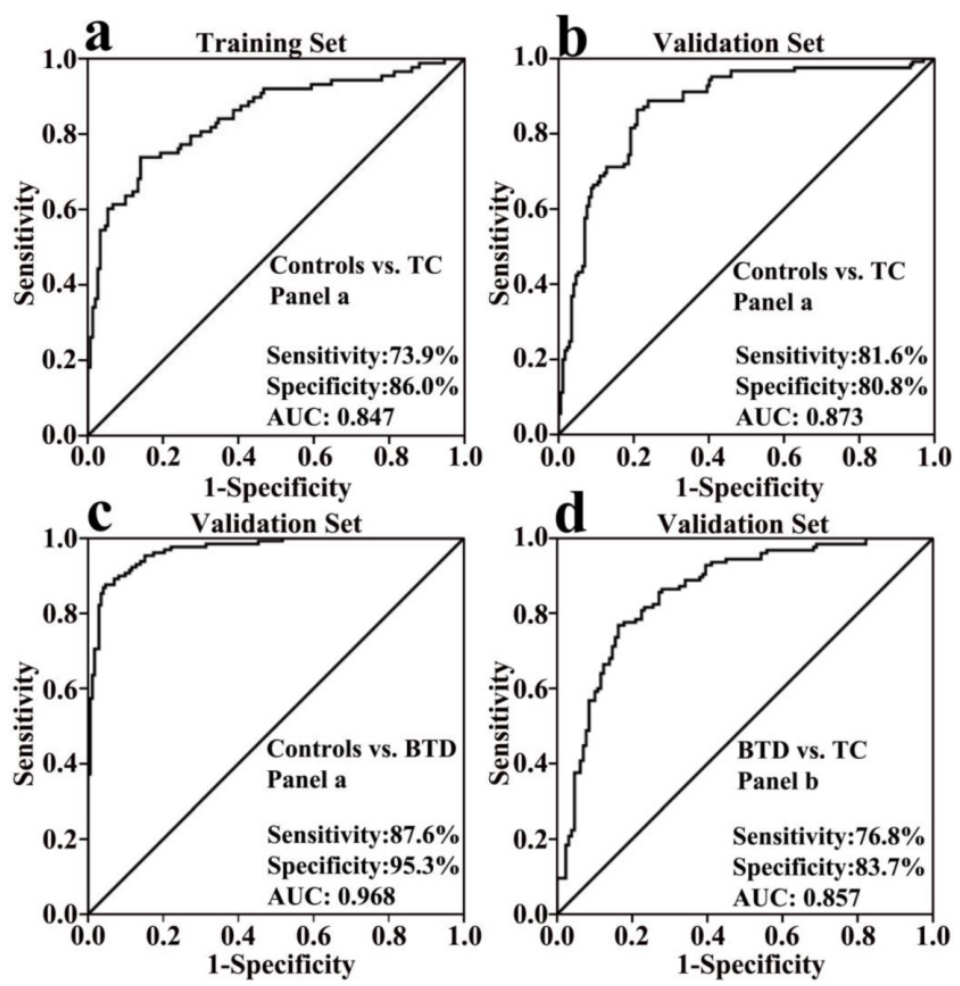

Figure 3. ROC curves. (a) panel a (a combination of $\mathrm{C}_{16: 1}, \mathrm{C}_{18: 3}, \mathrm{C}_{18: 2}, \mathrm{C}_{18: 1}, \mathrm{C}_{20: 4}$, and $\mathrm{C}_{22: 6}$ ) for differentiating the patients with thyroid cancer from healthy controls in the training set. (b) panel a for differentiating the patients with thyroid cancer from healthy controls in the validation set. (c) panel a for differentiating the patients with benign thyroid disease from healthy controls. (d) panel $b$ (a combination of $C_{16: 1}, C_{18: 2}, C_{20: 4}$, and $C_{22: 6}$ ) for differentiating the patients with thyroid cancer from the patients with benign thyroid disease.

As shown in Fig. 2, the levels of $C_{16: 1}, C_{18: 3}, C_{18: 2}$, $\mathrm{C}_{18: 1,}, \mathrm{C}_{20: 4}$, and $\mathrm{C}_{22: 6}$ in BTD patients relative to healthy controls were remarkably decreased. As shown in Table 3, $\mathrm{C}_{20: 4}, \mathrm{C}_{22: 6}$, PUFAs, and panel a have excellent diagnostic performance to differentiate BTD patients from controls, with the AUC values of $>0.91$, the sensitivities of $>83 \%$, and the specificities of $>86 \%$. The ROC curve for panel a is shown in Fig. 3c. In addition, it is worth noting that significantly decreased $C_{16: 1 \text {, }}$ $\mathrm{C}_{18: 2,}, \mathrm{C}_{20: 4}$, and $\mathrm{C}_{22: 6}$ in BTD patients were detected compared with TC patients (Fig. 2). Our findings indicate that the lipogenesis of $C_{16: 1}, C_{18: 2}, C_{20: 4}$, and $C_{22: 6}$ may involve in different metabolic pathways between BTD patients and TC patients.

Considering BTD patients and TC patients, the ROC curve analysis indicated that panel $b$ (a combination of $C_{16: 1}, C_{18: 2}, C_{20: 4}$, and $C_{22: 6}$ ) could exhibit excellent diagnostic ability to differentiate TC patients from BTD patients, with an AUC value of 0.857 , a sensitivity of $76.8 \%$, and a specificity of $83.7 \%$. The 
ROC curve for panel $b$ is shown in Fig. 3d. Recent years, several immunohistochemical markers, such as cytokeratin-19, galectin-3, HBME-1, fibronectin-1, and intracellular sodium/iodide symporter, or their combinations have been used to differentiate benign thyroid diseases from thyroid cancer, with high specificities of $>90 \%$, and sensitivities from $38 \%$ to $98 \%$ [13-16]. Other study has indicated that diffusion-weighted MR imaging as a promising non-invasive method to diagnose diseases has high diagnostic ability to differentiate benign from malignant in thyroid lesions, with an AUC value of 0.88 , a sensitivity of $76.5 \%$, and a specificity of $100 \%$ at b-value of $300 \mathrm{~s} / \mathrm{mm}^{2}$ [6], which is similar to our diagnostic ability obtained in this study. In addition, diffusion-weighted MR imaging technology is very complex, easily affected by instrument parameters.

\section{Conclusions}

In summary, this study has shown a comprehensive comparison of serum FFAs between healthy controls, BTD patients, and TC patients based on a large serum sample size. Significantly decreased $C_{16: 1 \text {, }}$ $\mathrm{C}_{18: 3}, \mathrm{C}_{18: 2}, \mathrm{C}_{18: 1}, \mathrm{C}_{20: 4}$, and $\mathrm{C}_{22: 6}$ in BTD patients and TC patients were observed compared with healthy controls, and significantly increased $\mathrm{C}_{16: 1}, \mathrm{C}_{18: 2}, \mathrm{C}_{20: 4}$, and $\mathrm{C}_{22: 6}$ in TC patients were detected compared with BTD patients. Our findings indicate that lipogenesis of $\mathrm{C}_{16: 1}, \mathrm{C}_{18: 2,}, \mathrm{C}_{20: 4}$, and $\mathrm{C}_{22: 6}$ may involve in different metabolic pathways between BTD patients and TC patients.

\section{Acknowledgements}

This study was supported by the National Natural Science Foundation of China (Grant no. 91029701) to Z. Li.

\section{Conflict of interest}

All authors disclose any affiliations that are consideration to be relevant and important with any organization that to our knowledge has any direct interest in the subject matter discussed.

\section{References}

1. Pellegriti G, Frasca F, Regalbuto C, Squatrito S, Vigneri R. Worldwide increasing incidence of thyroid cancer: update on epidemiology and risk factors. J Cancer Epidemiol 2013,2013: 965212.

2. Ito $Y$, Nikiforov $Y E$, Schlumberger $M$, Vigneri R. Increasing incidence of thyroid cancer: controversies explored. Nat Rev Endocrinol 2013,9: 178-184.

3. Nagataki S, Nystrom E. Epidemiology and primary prevention of thyroid cancer. Thyroid 2002,12: 889-896.

4. Castro MR, Gharib H. Continuing controversies in the management of thyroid nodules. Ann Intern Med 2005,142: 926-931.

5. Schueller-Weidekamm C, Kaserer K, Schueller G, Scheuba C, Ringl H, Weber M, Czerny C, Herneth AM. Can quantitative diffusion-weighted MR imaging differentiate benign and malignant cold thyroid nodules? Initial results in 25 patients. AJNR Am J Neuroradiol 2009,30: 417-422.

6. Wu Y, Yue X, Shen W, Du Y, Yuan Y, Tao X, Tang CY. Diagnostic value of diffusion-weighted MR imaging in thyroid disease: application in differentiating benign from malignant disease. BMC Med Imaging 2013,13: 23.
7. Wu LM, Chen XX, Li YL, Hua J, Chen J, Hu J, Xu JR. On the Utility of Quantitative Diffusion-Weighted MR Imaging as a Tool in Differentiation between Malignant and Benign Thyroid Nodules. Acad Radiol 2013,21: 355-363.

8. Das UN. Estrogen, statins, and polyunsaturated fatty acids: similarities in their actions and benefits-is there a common link? Nutrition 2002,18: 178-188.

9. Zhang YP, Qiu L, Wang YM, Qin XZ, Li ZL. High-throughput and high-sensitivity quantitative analysis of serum unsaturated fatty acids by chip-based nanoelectrospray ionization-Fourier transform ion cyclotron resonance mass spectrometry: Early stage diagnostic biomarkers of pancreatic cancer. Analyst 2014,139: 1697-1706.

10. Zhang YP, He CY, Qiu L, Wang YM, Zhang L, Qin XZ, Liu YJ, Zhang D, Li ZL. Serum unsaturated free Fatty acids: potential biomarkers for early detection and disease progression monitoring of non-small cell lung cancer. J Cancer 2014,5: 706-714.

11. Zhang YP, Song LN, Liu N, He CY, Li ZL. Decreased serum levels of free fatty acids are associated with breast cancer. Clinica Chimica Acta 2014,437: 31-37.

12. Kim KM, Jung BH, Lho DS, Chung WY, Paeng KJ, Chung BC. Alteration of urinary profiles of endogenous steroids and polyunsaturated fatty acids in thyroid cancer. Cancer Lett 2003,202: 173-179.

13. Barroeta JE, Baloch ZW, Lal P, Pasha TL, Zhang PJ, LiVolsi VA. Diagnostic value of differential expression of CK19, Galectin-3, HBME-1, ERK, RET, and p16 in benign and malignant follicular-derived lesions of the thyroid: an immunohistochemical tissue microarray analysis. Endocr Pathol 2006,17: 225-234.

14. Rossi ED, Raffaelli M, Mule A, Miraglia A, Lombardi CP, Vecchio FM, Fadda G. Simultaneous immunohistochemical expression of HBME-1 and galectin-3 differentiates papillary carcinomas from hyperfunctioning lesions of the thyroid. Histopathology 2006,48: 795-800.

15. Park YJ, Kwak SH, Kim DC, Kim H, Choe G, Park do J, Jang HC, Park SH, Cho BY, Park SY. Diagnostic value of galectin-3, HBME-1, cytokeratin 19, high molecular weight cytokeratin, cyclin D1 and p27(kip1) in the differential diagnosis of thyroid nodules. J Korean Med Sci 2007,22: 621-628.

16. Liu YY, Morreau H, Kievit J, Romijn JA, Carrasco N, Smit JW. Combined immunostaining with galectin-3, fibronectin-1, CITED-1, Hector Battifora mesothelial-1, cytokeratin-19, peroxisome proliferator-activated receptor-\{gamma\}, and sodium/iodide symporter antibodies for the differential diagnosis of non-medullary thyroid carcinoma. Eur J Endocrinol 2008,158: 375-384 